\title{
The investigation of the effects of some variables in the playoff games played in Turkey women's basketball super league between 2013-2017 on winning and losing
}

\author{
Şentuna M. ${ }^{1 \mathrm{ACDE}}$, Şentuna N. ${ }^{1 \mathrm{BD}}$, Özdemir N. ${ }^{\text {BCD }}$, Serter K. ${ }^{3 \mathrm{BDE}}$, Özen G. ${ }^{2 \mathrm{CD}}$ \\ ${ }^{1}$ Faculty of Sports Sciences, Department of Sports Management, Adnan Menderes University, Aydin, Turkey \\ ${ }^{2}$ Faculty of Health Sciences, Department of Sports Sciences, Democracy University, Izmir, Turkey \\ ${ }^{3}$ Faculty of Sports Sciences, Department of Sports Management, Marmara University, İstanbul, Turkey
}

Authors' Contribution:

A - Study design; B - Data collection; C - Statistical analysis; D - Manuscript Preparation; E - Funds Collection.

\begin{abstract}
Purpose: $\quad$ The aim of this research was to reveal positive and negative effects of the parameters causing to win or lose the game by investigating playoff series games played in Turkey Women's Basketball Super League between 20132017.

Material: $\quad$ The data used in the research was obtained from end of game statistics given by Turkish Basketball Federation (TBF). The variables measured (2-point field-goals percentage, 3-point field-goals percentage, free throw percentage, offensive rebound, defensive rebound, assist, steal, turnover, block, and free throws) were analyzed by Logistic Regression Analysis test method according to the winner and loser teams $(P<0.05)$, and the goodness of fit of the test model was measured by Hosmer and Lemeshow Test (Hosmer-Lemeshow goodness of fit test).

Results: Hosmer and Lemeshow goodness of fit test result was found 0.724 . The model was seen to be relatively small model (-2 Log likelihood, 139.731) Cox \& Snell R Square showed that it explained $47 \%$ of the variance, and Nagelkerke R Square showed that it explained $63 \%$ of the variance.

Conclusions: According to the results of the research, it was found that a one-unit increase in 2-point field-goals percentage 3-point field-goals percentage, offensive rebound, defensive rebound, steal and turnover variables had significant effects of winning and losing the game.

Keywords: Basketball, winners, losers, playoff.
\end{abstract}

\section{Introduction}

Basketball is a competitive sport with very ambiguous specific dynamics which is composed of technical fundamentals peculiar to itself and which is played by taking into account the limits of the players' time, space and participation [1]. According to Glick and Marcotte [2], basketball players should be able to understand and apply the complex movements and their variations in order to achieve high efficiency during a game, should be able to predict the movements of their teammates and rivals, and decide quickly on the implementation of technical elements or performance indicators. Sampaio [3] expresses that the performance of the winner teams stems from a better strategic and tactical environment by improving the players' more accurate and faster decision making abilities as well as having more opportunities to achieve their aims on the court.

In a basketball game, the coaches can win or lose the game especially with the decisions they make towards the end of the game in close-fought games when the game scores are very close. However, little is known about what factors usually distinguish success and failure at the end of the game. Usually, in order to increase the likelihood of success, detailed knowledge is required for the selection of the best tactical understanding, the strengths and weaknesses of the players, and different offensive and defensive strategies $[4,5]$.

The preparations for a team to be successful in basketball court involve the use of very complex strategies. One of the most effective strategies is the

\footnotetext{
(c) Şentuna M., Şentuna N., Özdemir N.,

Serter K., Özen G., 2018

doi:10.15561/20755279.2018.0306
}

statistical analysis (scouting report). A complete and comprehensive analysis helps to prepare for the game in the best way by gathering detailed information about the opponent team [3].

Determining player and team performances statistically is used to facilitate tactical decision making [4]. Statistical analyses in basketball sport are widely used to clarify the game quantitatively [6]. Performance and statistical analyses for the coaches are fundamental tools for team sports especially like basketball in order to have valid and reliable information about their own teams and their rivals [7]. Coaches and researchers use this information to assess the variables such as how each player contributes to team performance, the importance of certain roles within the game, and the advantages of being the home team [8].

Men's and women's basketball teams in Turkey have had considerable success in the recent years in the international arena both in the clubs and national team levels. Besides, many athletes that have competed in Turkish leagues are being transferred to NBA teams, which is known as the world's best basketball league. However, it is noticed that there are very few studies conducted on team and player performances from a holistic point of view. The aim of this study is to reveal the variables that directly affect winning and losing in a basketball game, and provide an insight regarding which variables should be allocated more time during the training periods while the coaches train their teams.

Material and methods

Participants: This research is composed of 94 games 
played in the playoffs of the five seasons of Women's Basketball Super League organized by Turkish Basketball Federation (TBF) between 2013-2017. The results of the study were obtained from the statistics of the end of game statistics that TBF published on the web page beginning from 2013 season [9].

The reason why only playoff games were included in the survey was the fact that they were the games played between the teams with relatively equal powers, and that the results of the research could be more significant.

Research Design: The statistical data for each game was classified into two separate categories as winner and loser, and they were used as dependent variables in the study. The variables found in the end of game statistics were in 2-point field-goals percentage, 3-point field-goals percentage, free throw percentage, offensive rebound, defensive rebound, assist, steal, turnover, block, and foul points and these variables were used as independent variables in the research.

Statistical Analysis: Logistic Regression Analysis test method was used for the analysis of the data and the test model's goodness of fit was measured by the Hosmer and Lemeshow Test. The explanatory power of the model was assessed with Cox \& Snell R Square and Nagelkerke R Square values, and 95\% CI values (OR-odds ratio values that would be obtained from 95 of the studies when the study was repeated 100 times) were determined as confidence interval.

In statistics, Logistic Regression Analysis [10] is a regression model in which the dependent variable is binary. The binary logistic analysis model is used to calculate the likelihood of the binary (dichotomous) result over one or more independent variables. There may be continuous, sequential or categorical independent variables in binary logistic regression analysis. While a multivariate model is being developed, the presence of a high degree of correlation (multikolliniarite) among the independent variables that will be included in the model should be investigated. It is expected that there should be at least 10 cases for each independent variable to be included in multivariate logistic regression analysis [11]. In this study, there were 10 independent variables in this study and 94 × $2=188$ (winner/loser) cases were defined for each of them.

Hosmer-Lemeshow test is a statistical test method used for the goodness of fit in logistic regression models and is often used in risk estimation models. The test evaluates whether the observed state ratios in the subgroups of the model sample are matched with the expected state ratios. Hosmer-Lemeshow test specifically identifies the subgroups as one-tenth of the appropriate risk values. The models are named as expected and observed event rates of well-adjusted similar subgroups [11-13]. In order for the model to be supposed as good, it is demanded that "sig" value is greater than 0.05 [14].

\section{Results}

In TBF Women's Basketball Super League, 100 games were played in the playoffs of the five seasons between 2013-2017. The statistics of one game for quarter-finals and one for semi-finals in 2013 season; two games for quarter-finals and one game for semi-finals in 2014 season; and one game for the finals in 2015 season were not published so 94 games were included in the study.

The mean scores of the winner teams were 13.62, 2-point field-goals percentage mean scores were 5.62, 3 -point field-goals percentage mean scores were 8.19, free throw mean scores were 2.03, offensive rebound mean scores were 1.1, defensive rebound mean scores were 3.41 , assist mean scores were 4.16 , steal mean scores were 1.88 , and block mean scores were 0.60 more than those of the loser teams. Turnover mean scores of the loser teams were 1.92, and foul mean scores were 0.19 more than those of the winner teams.

In logistic regression analysis, the winner team values were taken as the dependent variable reference point

Table 1. Playoff games played between the years of 2013-2017.

\begin{tabular}{lllllll}
\hline Playoff & $\mathbf{2 0 1 3}$ & $\mathbf{2 0 1 4}$ & $\mathbf{2 0 1 5}$ & $\mathbf{2 0 1 6}$ & $\mathbf{2 0 1 7}$ & Total \\
\hline $\mathbf{1 / 4}$ finals & 8 & 7 & 9 & 9 & 9 & 42 \\
$\mathbf{1} / \mathbf{2}$ finals & 6 & 5 & 6 & 8 & 6 & 31 \\
Final & 5 & 5 & 3 & 3 & 5 & 21 \\
Total & 19 & 17 & 18 & 20 & 20 & $\mathbf{9 4}$ \\
\hline
\end{tabular}

Table 2. The mean and difference values of the independent variables according to winner and loser teams.

\begin{tabular}{llllllllllll}
\hline & Point & $\begin{array}{l}\mathbf{2} \\
\text { point } \\
\mathbf{\%}\end{array}$ & $\begin{array}{l}\mathbf{3} \\
\text { point } \\
\mathbf{\%}\end{array}$ & $\begin{array}{l}\text { Free } \\
\text { throws \% }\end{array}$ & $\begin{array}{l}\text { Off. } \\
\text { Reb. }\end{array}$ & $\begin{array}{l}\text { Def. } \\
\text { Reb. }\end{array}$ & Assist & Steal & Turnover & Block & Foul \\
\hline Winner & 73.83 & 49.40 & 35.67 & 74.93 & 10.63 & 27.20 & 17.32 & 7.00 & 12.02 & 2.20 & 16.50 \\
Loser & 60.21 & 43.78 & 27.48 & 72.90 & 9.2 & 23.79 & 13.16 & 5.12 & 13.94 & 1.60 & 16.69 \\
Diff. & 13.62 & 5.62 & 8.19 & 2.03 & 1.11 & 3.41 & 4.16 & 1.88 & -1.92 & 0.60 & -0.19 \\
\hline
\end{tabular}

Note: Off. Reb. - Offensive Rebounds; Def. Reb. - Defensive Rebounds; Diff. - Difference. 
(winner 0, loser 1). According to Omnibus Tests of Model Coefficients, Chi-square value of the model coefficient was found 120,892 and $\mathrm{P}$ value was found 0,000 (P $<0,05)$ when 10 parameters were taken into account. The fact that $\mathrm{P}$ value is $\mathrm{P}<0.05$ indicates that the model is significant and good. When Model Summary was analyzed, it was seen that the model was a relatively small model according to -2 Log Likelihood (139.731), which indicated that Cox \& Snell R Square explained $47 \%$ of the variance and Nagelkerke R Square explained $63 \%$ of the variance. When Hosmer-Lemeshow goodness of fit test was examined, it was found that Chi-square value was 5.307 and $P$ value was 0.724 . The fact that $P$ value was $\mathrm{P}>0.05$ and close to 1 indicated that the goodness of fit was high.

According to logistic regression analysis results, the 2-point field-goals percentage, the 3-point field-goals percentage, offensive rebound, defensive rebound, steal (negative) and turnover (positive) variables were found to have significant effect on winning and losing.

Accordingly, the fact that 2-point field-goals percentage was one point low increased the probability of losing the game by 1.21 times $(1 / 0.821)$, that 3 -point field-goals percentage was one point low increased the probability of losing the game by 1.11 times (1/0.895), that the number of offensive rebounds was one low increased the probability of losing the game by 1.31 times $(1 / 0.760)$, that the number of defensive rebounds was one low increased the probability of losing the game by 1.34 times $(1 / 0.745)$, that the number of steals was one low increased the probability of losing the game by 1.53 times $(1 / 0.653)$, and that the number of turnovers was one low increased the probability of winning the game by 1.193 times.

\section{Discussion}

In the research, the positive and negative effects of some basic techniques (variables) used in a basketball game on winning and losing a game was investigated. In international literature, there are many studies investigating the indicators that affect winning and losing in basketball games [4, 14-16]. However, there is not enough information in any of them on the effect of what will cause winning or losing if there is one unit of increase in the variables.

Leicht et al. [17] revealed in their study which investigated what team performance indicators were in the women's basketball games in Athens-2004, Beijing-2008, London-2012 and Rio de Janeiro-2016 Olympic Games that when defensive rebound, score percentage, steal and turnover variables come together by exhibiting high performance, they increased the probability of winning in the games by $91.1 \%$, and when these variables were low, they increased the probability of losing by $96.7 \%$. These findings seem to support our conclusions.

In another study conducted [18], it was aimed to identify the differences in the qualitative and quantitative indicators of the best eight teams' shooting performances in the European Women's Basketball Championship games between 1995 and 2011. It was revealed that the highest mean score of the winner teams was $78.3 \pm 8.1$, the highest mean score in low post and high post shots was $52.9 \pm 6.5$, the highest mean score in long distance shots was $17.4 \pm 4.6$, and 3-point field-goals percentages were 34.4 \pm 5.9 . These results show that 2-point and 3-point shots and their percentages are effective on winning and thus, they support the results that we have found significantly in our research.

In a study [19], the performance of ball possession in men's and women's basketball according to game periods was investigated. It was determined that the women possessed the ball more under both hoops in the first five minutes and used different defensive systems, while possessing the ball became more important for men in

Table 3. Significance, probability and reliability limit values of the logistic model.

\begin{tabular}{lllllllll}
\hline & $\beta$ & SE & Wald & Df & Sig. & Exp( $\beta$ ) & \multicolumn{2}{c}{ 95\% C.I. for Exp( $\beta$ Lower } \\
Upper
\end{tabular}

Note: $P<0,05 ; \beta$ - The estimated coefficient; SE - Standard error of the estimate; Wald - Wald value; Df - Degree of freedom; Sig. - Significance value; $\operatorname{Exp}(\beta)$ - Exponentiated $\beta$ /odds ratio; C.I. for $\operatorname{Exp}(\beta)$ - Confidence interval for Exponentiated $\beta$ /odds ratio. 
the last five minutes of the game in terms of winning the match. This result supports the conclusion of our research that steal and turnover variables were important in terms of possessing the ball more.

In another study [20], quarter-final, semi-final and final basketball games played at the 2008 Beijing Olympic Games were examined and it was investigated what the defense indicators were in the winner and loser teams in order to achieve success. According to the results of the research, it was stated that man-to-man defense was frequently used by both winner and loser teams, and that the loser teams used zone defense more. Besides, they expressed that the winner teams put two times more pressure than the loser teams and that both the winner and loser teams reached the highest percentage of impact when they put pressure in the front line. This may cause the team to make more steals or the opponent team to make more turnovers under pressure. In this research, the fact that steal and turnover variables had significant effect may be explained by the fact that they had a positive or negative effect on winning and losing.

\section{References}

1. Ferreira AEX, De Rose JrD. Basquetebol: Técnicas e Táticas. Uma abordagem didático-pedagógica [Basketball: Techniques and Tactics. A didactic-pedagogical approach]. São Paulo: EPU; 2003. (In Spanish)

2. Glick ID, Marcotte DB. Psychiatric Aspects of Basketball. Journal of Sport Medicine and Physical Fitness, 1989; 29(1): 104-112.

3. Sampaio J, Drinkwater EJ, Leite N. Effects of Season Period, Team Quality, and Playing Time on Basketball Players' Game-Related Statistics. European Journal of Sport Sciences, 2010; 10(2): 141-149.

4. Csataljay G, O'Donoghue P, Hughes MD, Dancs H. Performance Indicators that Distinguish Winning and Losing Teams in Basketball. International Journal of Performance Analysis in Sport, 2009; 9(1):60-66.

5. Seifried C. Maximize Basketball Success With a Scouting Report, Strategies. A Journal for Physical and Sport Educators, 2004; 18(1): 26-29.

6. Madarame H. Game-Related Statistics Which Discriminate Between Winning and Losing Teams in Asian and European Men's Basketball Championships. Asian J Sports Med. 2017; 8(2): 42727.

7. Sampaio J, Janeira M, Ibáñez SJ, Lorenzo A. Discriminant Analysis of Game Related Statistics Between Basketball Guards, Forwards And Centres in Three Professional Leagues. European Journal of Sports Sciences, 2006; 6(3): 173-178.

8. Pollard R. Home Advantage in Football: A Current Review of an Unsolved Puzzle. The Open Sports Sciences Journal, 2008; 1: 12- 14

9. Türkiye Basketbol Federasyonu, Kadınlar Basketbol Süper Ligi. [Turkey Basketball Federation, Women's Basketball Super League] 2018 January-April [cited 2018 January 1] Available from: http://www.tbf.org.tr/ligler/kbsl/arsiv/ maclar (In Turkish)

10.Kılıç S. Binary Logistic Regression Analysis. Journal of Mood Disorders, 2015;5(4):191-194. (In Turkish)

11.Hosmer DW, Lemeshow S. Applied Logistic Regression.

\section{Conclusions}

As a result, considering the negative and positive parameters affecting winning and losing in the playoffs of the five seasons in TBF Women's Basketball Super League between 2013-2017, it was revealed that in order to be the winner teams in playoff games, they had to make more steals and less turnovers, increase the percentage of 2-point and 3-point field-goals, and the number of offensive and defensive rebounds. Taking into account the fact that one unit increase in these variables has a significant effect on winning and losing, it can be stated that an increase of more than one unit during the game will greatly affect winning and losing. For this reason, it is thought and suggested that the coaches devote more time in the trainings to improve the skills and attentions of their players on these parameters and should make ne trainings. This study can be conducted by taking into consideration the data of the games played during all seasons, and can be repeated on male teams and in different leagues.

\section{Conflict of interests}

The authors declare that there is no conflict of interests.

\section{New York: John Wiley and Sons; 2000.}

12.Bircan H. Lojistik Regresyon Analizi: Tip Verileri Üzerine Bir Uygulama [Logistic Regression Analysis: An Application on Medical Data]. Kocaeli Üniversitesi Sosyal Bilimler Enstitüsü Dergisi, 2004;2: 185-208. (In Turkish)

13.Hosmer DW, Lemeshow S. Goodness of Fit Tests for the Multiple Logistic Regression Model. Communications in Statistics, 1980;9:1043-1069.

14.Junior DR. Statistical Analysis of Basketball Performance Indicators According to Home/Away Games and Winning and Losing Teams. Journal of Human Movement Studies, 2004; 47:327-336

15.Conte D, Tessitore A, Gjullin A, Mackinnon D, Lupo C, Favero T. Investigating the Game-Related Statistics And Tactical Profile in NCAA Division I Men's Basketball Games. Biology of Sport, 2018;35(2):100-108.

16.Lorenzo A, Gómez MA, Ortega E, Ibáñez SJ, Sampaio J. Game Related Statistics Which Discriminate Between Winning and Losing Under-16 Male Basketball Games. Journal of Sports Science and Medicine, 2010; 9: 664-668.

17.Leicht SA, Gomez MA, Woods CT. Team Performance Indicators Explain Outcome during Women's Basketball Matches at the Olympic Games. Sports. 2017; 5(96): 2-8.

18.Kreivyte R, Emeljanovas A, Sporıš G, Knjaz D, Vučković G, Milanović Z. Shooting Performance Did Not Change In Elite Women's National Basketball Teams From 1995 To 2011. Annales Kinesiologiae, 2013;4(1):45-56.

19.Gomez MA, Lorenzo A, Ibañez SJ, Sampa1o J. Ball Possession Effectiveness in Men's and Women's Elite Basketball According to Situational Variables in Different Game Periods. Journal of Sports Sciences, 2013;31(14): $1578-1587$.

20.Álvarez A, Ortega E, Gómez MA, Salado J. Study Of The Defensive Performance Indicators in Peak Performance Basketball. Revista de Psicología del Deporte, 2009;18:379384. 


\section{Information about the authors:}

Şentuna M.; (Corresponding author); http://orcid.org/0000-0001-7728-7933; tarumnil@gmail.com; Faculty of Sports Sciences, Department of Sports Management, Adnan Menderes University; TR-09100, Aydın, Turkey.

Şentuna N.; http://orcid.org/0000-0002-2014-6870; Faculty of Sports Sciences, Department of Sports Management, Adnan Menderes University; TR-09100, Aydın, Turkey.;; Özdemir N.: http://orcid.org/ 0000-0002-6124-6982; nozdemir974@gmail.com; Faculty of Health Sciences, Department of Sports Sciences, Democracy University, TR- 35140, Izmir, Turkey.

Serter K.; http://orcid.org/0000-0002-5089-8467; Faculty of Sports Sciences, Department of Sports Management, Marmara University; TR-34815, İstanbul, Turkey.

Özen G.; http://orcid.org/0000-0003-0360-5358; Faculty of Health Sciences, Department of Sports Sciences, Democracy University; TR- 35140, İzmir, Turkey.

Cite this article as: Şentuna M, Şentuna N, Özdemir N, Serter K, Özen G. The investigation of the effects of some variables in the playoff games played in Turkey women's basketball super league between 2013-2017 on winning and losing. Physical education of students, 2018;22(3):146-150. doi:10.15561/20755279.2018.0306

The electronic version of this article is the complete one and can be found online at: http://www.sportedu.org.ua/index.php/PES/issue/archive

This is an Open Access article distributed under the terms of the Creative Commons Attribution License, which permits unrestricted use, distribution, and reproduction in any medium, provided the original work is properly cited (http://creativecommons.org/licenses/by/4.0/deed.en)

Received: 06.05.2018

Accepted: 01.06.2018; Published: 27.06.2018 